\title{
Long-period upper mesosphere temperature and plasma scale height variations derived from VHF meteor radar and LF absolute reflection height measurements
}

\author{
C. Jacobi ${ }^{1}$ and D. Kürschner ${ }^{2}$ \\ ${ }^{1}$ Institute for Meteorology, University of Leipzig, Stephanstr. 3, 04103 Leipzig, Germany \\ ${ }^{2}$ Institute of Geophysics and Geology, University of Leipzig, Collm Observatory, 04779 Wermsdorf, Germany
}

\begin{abstract}
The change of ionospheric absolute reflection heights $\mathrm{h}$ of low-frequency (LF) radio waves at oblique incidence in the course of the day is measured at Collm Observatory $\left(51.3^{\circ} \mathrm{N}, 13.0^{\circ} \mathrm{E}\right)$ using $1.8 \mathrm{kHz}$ sideband phase comparisons between the sky-wave and the ground wave of a commercial $177 \mathrm{kHz}$ transmitter (Zehlendorf, reflection point at $52.1^{\circ} \mathrm{N}, 13.2^{\circ} \mathrm{E}$ ). Plasma scale height estimates $\mathrm{H}$ are calculated from the decrease/increase of $h$ in the morning/evening. The day-to-day variations of $\mathrm{H}$ are compared with those of daily mean temperatures at $90 \mathrm{~km}$, measured with a VHF meteor radar (36.2 MHz) at Collm and using the amplitude decay of meteor reflections. A good qualitative correspondence is found between the two data sets. Since mesospheric long-period temperature variations are generally accepted to be the signature of atmospheric planetary waves, this shows that LF reflection height measurements can be used for monitoring the dynamics of the upper middle atmosphere.
\end{abstract}

\section{Introduction}

The dynamics of the mesosphere/lower thermosphere (MLT) region at $80-100 \mathrm{~km}$ altitude is forced through wave coupling, so that MLT mean circulation and temperature trends may indicate possible long-term trends of wave activity and vice versa. Usually, when atmospheric waves are considered, one distinguishes between short-period gravity waves, tides with periods of $24 \mathrm{~h}$ and harmonics, and other planetary waves in the so-called long-period range up to about 30 days.

Planetary wave analyses often describe either the total variability of winds or temperature in the period interval to about 30 days (Jacobi et al., 1998; Bittner et al., 2000), or they focus on one or few specific waves as, e.g. Rossby normal modes like the quasi 2-day wave (Chshyolkova et al.,

Correspondence to: C. Jacobi (jacobi@uni-leipzig.de)
2005). Regarding long-term trends and possible indicators for climate variability, there is a tendency for a slight increase of overall day-to-day variability in the 1980's and 1990's (Jacobi et al., 1998, 2000), but this result is based on only few datasets, and thus far is neither confirmed by a hemispheric or global analysis, nor thus far explained through theoretical consideration. A more indirect analysis of planetary waves was performed using radio wave absorption variations (e.g. Lastovicka et al., 1994). These analyses showed a possible positive trend, but this is intermittent (Lastovicka, 2002).

To summarise, the current knowledge on planetary wave activity in the MLT is still incomplete, mainly because of the lack of long homogeneous time series. To contribute to the available data base and providing a potential for additional wave analysis, we propose here to use the diurnal change of lower E-region low-frequency (LF) reflection heights as an indicator for daily temperatures and to derive planetary waves from these analyses. Using LF radio waves as a tracer for synoptic measurements has been done since several decades (Entzian et al., 1976; Lauter et al., 1977). Phaseheight measurements (von Cossart and Entzian, 1976) use LF transmitters located at a distance of several hundred kms from the receiver, with reflection heights well below $85 \mathrm{~km}$ during daytime. Here, we make the first attempt to analyse scales heights using LF waves on a short propagation path.

\section{LF height measurements and analysis of scale height}

Low frequency $177 \mathrm{kHz}$ radio waves from a commercial radio transmitter are registered at Collm Observatory, Germany $\left(51.3^{\circ} \mathrm{N}, 13.0^{\circ} \mathrm{E}\right.$, distance to transmitter $\left.170 \mathrm{~km}\right)$. The virtual reflection heights h', referring to the reflection point at $52.1^{\circ} \mathrm{N}, 13.2^{\circ} \mathrm{E}$, are estimated using measured travel time differences between the ground wave and the reflected sky wave through phase comparisons on sporadic oscillation bursts of the amplitude modulated LF radio wave in a small

Published by Copernicus GmbH on behalf of the URSI Landesausschuss in der Bundesrepublik Deutschland e.V. 


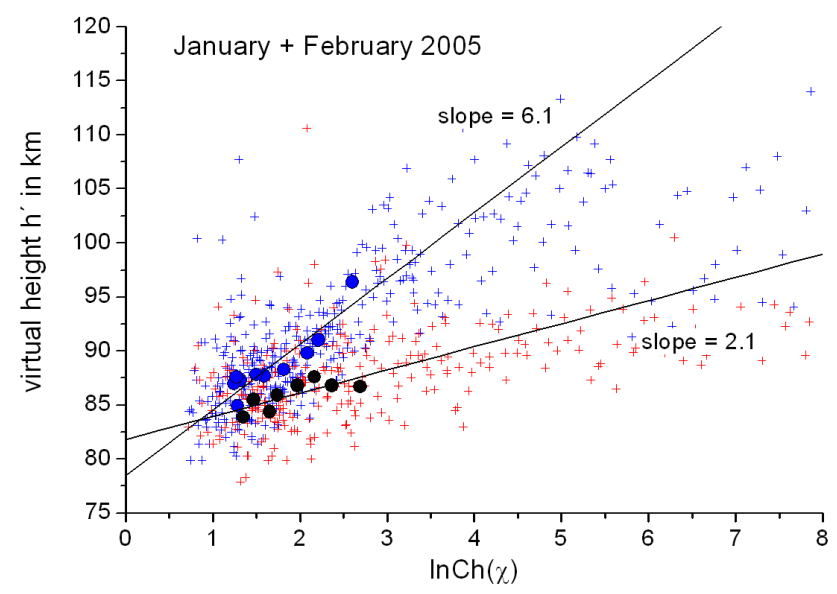

Fig. 1. Virtual height h' measured on $177 \mathrm{kHz}$ vs. the logarithm of the Chapman function $C h(\chi)$, for half-hourly mean data of all days in January and February 2005. Median values of h' are given for $C h(\chi)<3$, and for forenoon (blue) and afternoon (red) data separately. The slopes are calculated from the median values.

modulation frequency range around $1.8 \mathrm{kHz}$ (Kürschner et al., 1987). The reflection height measurements have started in September 1982 and are carried out continuously since then, even after the temporal change to digital broadcasting in September 2005.

The height resolution of an individual reflection height measurement is nearly $2 \mathrm{~km}$. The data are combined to halfhourly means that consist of approximately 6000 individual values on an average. Essentially caused by the variability of reflection heights the $1 \times \sigma$ variation of the half-hourly mean is in the order of $3 \mathrm{~km}$ below $95 \mathrm{~km}$ and slightly more than $5 \mathrm{~km}$ near an altitude of $100 \mathrm{~km}$.

Half-hourly virtual reflection heights range between roughly $82 \mathrm{~km}$ during daytime and nearly $100 \mathrm{~km}$ during nighttime for the ordinary component. Especially in winter in the late night and early morning hours, and also in some midsummer nights, wave propagation is subject to stronger magnetoionic splitting into the ordinary and extraordinary component, with very large virtual reflection heights of the latter. In this case the half-hourly mean height consists of a mixture of both components with unknown weighting, so that these data will not be used here. During daylight hours, particularly in the summer months height measurements are not possible due to strong D-region absorption of sky waves then.

Assuming essentially equilibrium between ionisation and recombination, one single gas, an isothermal atmosphere, monochromatic radiation, and with that resulting a Chapman profile of the electron density, the height $h$ of the layer maximum changes with zenith angle of the sun, $\chi$, as:

$h=h_{0}+H \ln C h(\chi)$, with $\mathrm{h}_{0}=\mathrm{h}(\chi=0), H=\mathrm{RT} / \mathrm{Mg}$ as the plasma scale height ( $\mathrm{T}$ as absolute temperature, $\mathrm{R}$ as molar gas constant, $\mathrm{g}$ as the acceleration due to gravity and $\mathrm{M}$ as molecular mass) and the Chapman function $C h(\chi)$. If $\chi<75^{\circ}$ then $C h(\chi) \approx 1 / \cos \chi$ is a suitable approximation in the case that the curvature of the earth is neglected. Experimentally, a relationship similar to Eq. (1) has been found between the virtual reflection height h' of LF waves below the layer maximum and the solar zenith distance as in the case of Chapman layer maximum:

$h^{\prime}=h_{0}^{\prime}+H \ln C h(\chi)$.

Therefore, plotting the logarithm of the Chapman function against the virtual reflection height should provide, in a first approximation, a nearly linear correspondence, with the slope of the regression line as a scale height estimate:

$H=\frac{\Delta h^{\prime}}{\Delta \ln (C h(\chi))}$.

In the case of a delay of the reflection height curve with respect to the solar zenith distance, i.e. for the case of nonequilibrium, the slope differs from $\mathrm{H}$. While von Cossart (1976) for mesospheric data used the average of forenoon and afternoon measurements and obtained a good correspondence with rocket measurements, the delay in the lower Eregion may differ from that one at lower heights. Moreover, the difference between real and virtual reflection heights can be substantial and reach more than $2 \mathrm{~km}$ in the D-region and more than $5 \mathrm{~km}$ in the lower E-region. Therefore, the results of $\mathrm{H}$ estimations have to be considered as qualitative. In addition, at higher altitudes the derived $\mathrm{H}$ values are smaller, especially in winter (Entzian et al., 1976; Lauter et al., 1977), which is known as the so-called "winter anomaly". Caused by the comparatively short distance between transmitter and receiver, which is connected with a steep incidence angle, the reflection heights on $177 \mathrm{kHz}$ lies above those in earlier works (75-95 km, Lauter et al., 1966). Thus, differences between forenoon and afternoon just as summer and winter behaviour on the $\mathrm{H}$ estimates are to be expected. As an example, for 2 month time interval in Fig. 1 h' vs. $\ln (C h(\chi))$ is shown separately for the forenoon h' decrease (blue symbols) and the afternoon h' increase (red symbols). Median values for these two cases are given in the figure, and slopes are calculated. Clearly, the slopes are different and the change of slope for larger $\ln (C h(\chi))$ values, i.e. for low elevation angles, can also be seen. Therefore, slopes have been calculated using the forenoon and afternoon median values only in the range of $\ln (C h(\chi))<3$. For the afternoon the resulting slope is clearly too small, while the values for the forenoon are more realistic taking into account earlier results from other authors (e.g. von Cossart, 1976) and the temperature climatology of the mesopause region (e.g. CIRA86, Fleming et al., 1990). In the following we shall use forenoon data only.

Figure 1 also shows that sometimes at small values of $\ln (C h(\chi)$ large values of $h$ ' are measured. These are owing 

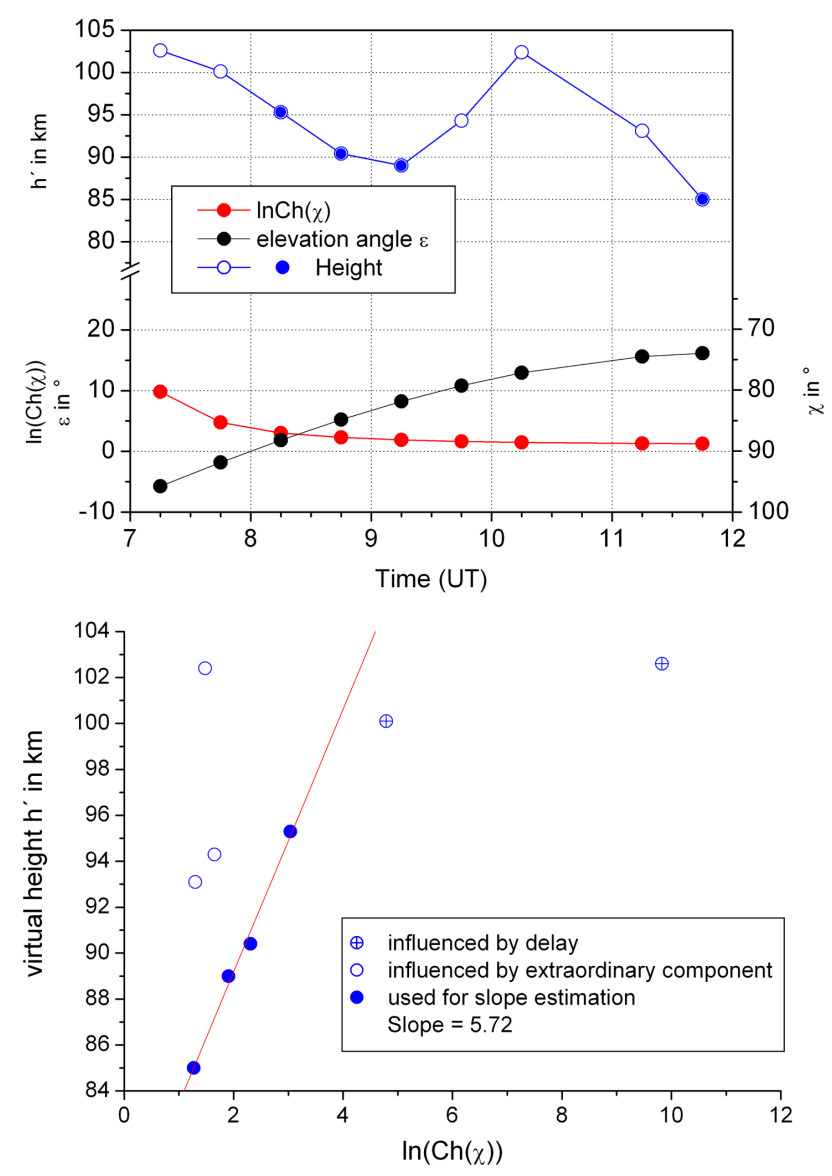

Fig. 2. Example of scale height $\mathrm{H}$ estimation for the forenoon of 10 January 2005. Upper panel: time series of logarithm of Chapman function $\ln C h(\chi)$, elevation angle $\varepsilon=90^{\circ} \chi$, and virtual height h'. Lower panel: virtual height h' vs. $\ln C h(\chi)$. Solid blue dots denote h' data points used for $\mathrm{H}$ estimation.

to reflections from the extraordinary component mixed with the ordinary component. These data cannot be used for the analysis. In Fig. 1 they are automatically discarded since we take the median of two months of data, but on a single day, as is exemplarily shown in Fig. 2 these data can completely alter the profile. As shown in the figure, data that are obviously dominated by the extraordinary component are discarded. It should be noted that, for single days, the analysis of the scale height my be done from only very few data points and large uncertainty resulting from that.

\section{Mesopause temperatures derived from VHF meteor radar measurements}

VHF meteor radars measure the radio wave reflection from the ionised trails of meteors entering the Earth's atmosphere. The decay time of the signal is detected from so-called underdense meteor trails, i.e. from those trails whose reflectiv-

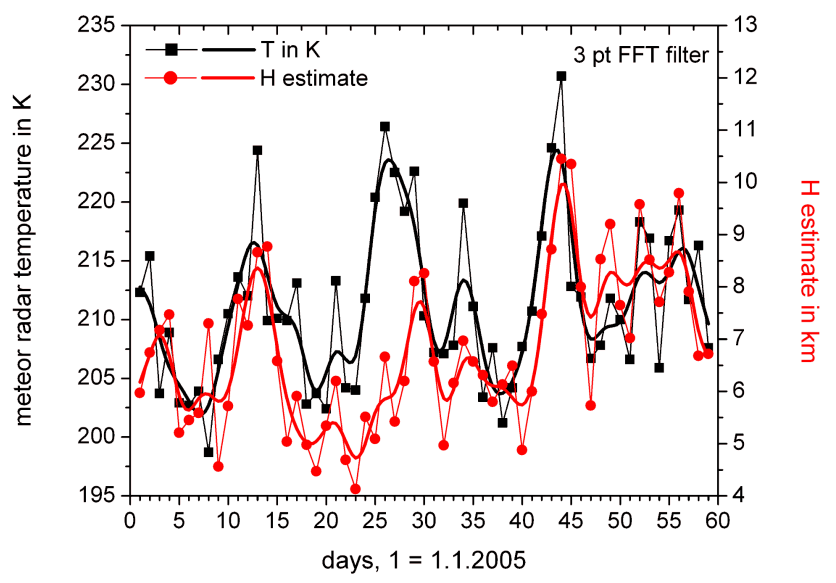

Fig. 3. Time series of scale height $\mathrm{H}$ estimates and meteor radar temperatures T during January and February 2005. The thick solid lines are smoothed data using a 3 point FFT filter.

ity is determined by their electron density, which decreases with time due to diffusion (Hocking, 1999, Hocking et al., 2001). The amplitude decreases exponentially depending on the ambipolar diffusion coefficients $D_{a}$ :

$A=A_{0} \exp \left\{-\frac{16 \pi^{2} D_{a}}{\lambda^{2}} t\right\}$,

with $A$ as the signal amplitude, $\lambda$ as the radar wavelength and $t$ as time. Measuring the decay of the amplitude allows to estimate $D_{a}$. The diffusion coefficient is proportional to the ratio of temperature squared and pressure. Introducing a temperature gradient from an empirical model and using exponential pressure decay with height, one obtains an equation for the temperature in dependence of the diffusion coefficient change with height:

$$
\frac{d \ln D_{a}}{d z}=-2 \frac{d T / d z}{T_{0}}+\frac{m g}{k T_{0}},
$$

to be solved for $T_{0}$. Details can be found in Hocking (1999). Temperatures estimated with this method has been presented by Hocking et al. (2004) and Singer et al. (2004), who also showed validation results using rocket and ground-based optical methods. Temperature data are available as daily means at $90 \mathrm{~km}$ height, which is approximately the height where maximum meteor rates are found.

At Collm Observatory, a SKiYMET meteor radar is operated on $36.2 \mathrm{MHz}$ since summer 2004. From meteor reflections mesopause region hourly wind profiles and daily temperatures are derived that roughly apply to a circle around Collm with $300 \mathrm{~km}$ diameter, and for heights between $80-100 \mathrm{~km}$. 


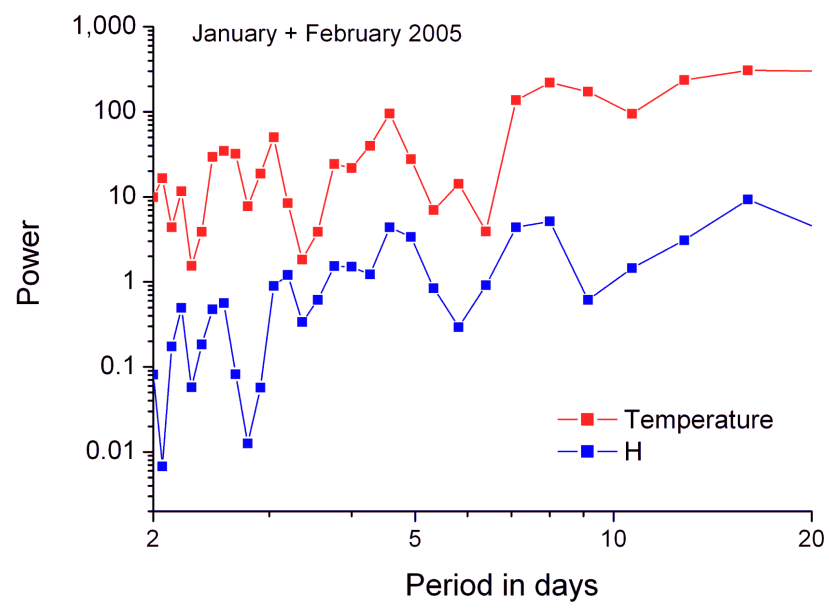

Fig. 4. Power spectra of scale height estimates and meteor radar temperatures.

\section{Results and discussion}

The time series of meteor radar derived daily temperatures in early 2005 is shown in Fig. 3. The daily scale height estimates after Eq. (3) are added. Both curves have been subjected to a 3 point FFT filter (thick solid line) to suppress random irregularituies from the measurement and analysis uncertainty. The temperature and $\mathrm{H}$ curves show the same qualitative tendency. Obviously, the dominating day-to-day and long-period changes are visible in both datasets, indicating that their variability is of the same origin, i.e. the MLT temperature change. Power spectra of both parameters are shown in Fig. 4. Peaks are correspondingly found for periods of 3,5 , and 8 days.

Two months of LF absolute reflection height data has been used to derive scale height estimates in the lower E-region. These data has been compared to meteor radar temperatures. The results are clearly qualitative. In addition, the influence of the extraordinary component of the LF wave on the results has carefully to be analysed and removed from the data set. This, however, makes the analysis somewhat complicated, and increases the potential errors.

Nevertheless, the long-period variations of both parameters available after low pass filtering are in adequate agreement, indicating that the temperature effect on the diurnal scale height change is inferable using the $177 \mathrm{kHz}$ measurements at Collm, with short propagation distances. Since LF height measurements are available for more than 2 decades, this provides the opportunity to analyse planetary waves and their long-term variations and trends.

Acknowledgements. This study has been partly supported by DFG under grant JA 836/19-1 (CPW-TEC) within the SPP 1176 "CAWSES - Climate And Weather of the Sun-Earth System".

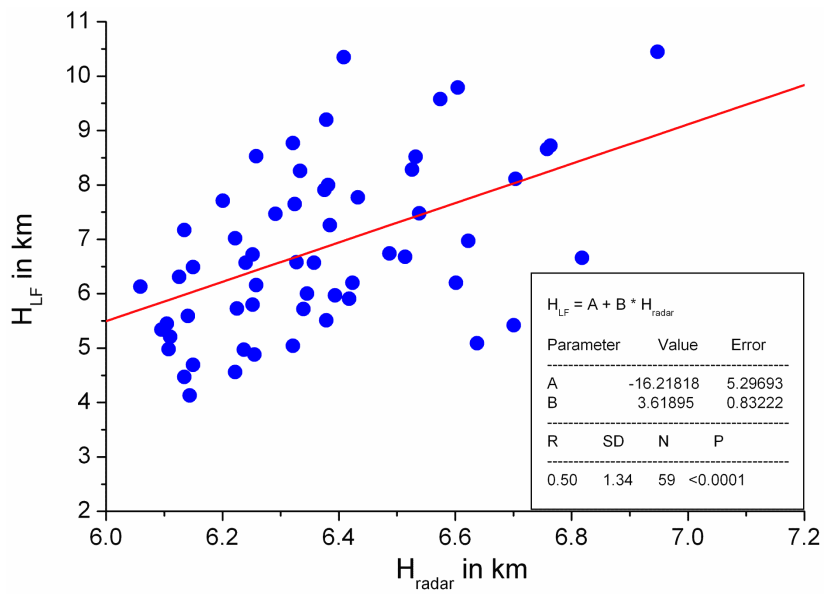

Fig. 5. Scale height estimates $\mathrm{H}_{L F}$ calculated from $L F$ reflection height changes vs. scale heights $\mathrm{H}_{\text {radar }}$ calculated from meteor radar.

\section{References}

Bittner, M., Offermann, D., and Graef, H.H.: Mesopause temperature variability above a midlatitude station in Europe, J. Geophys. Res., 105, 2045-2058, 2000.

Chshyolkova, T., Manson, A. H., and Meek, C. E.: Climatology of the quasi two-day wave over Saskatoon $\left(52^{\circ} \mathrm{N}, 107^{\circ} \mathrm{W}\right): 14$ Years of MF radar observations, Adv. Space Res., 35, 20112016, 2005.

Entzian, G., Lauter, E. A , and Taubenheim, J.: Synoptic monitoring of the mesopause region using D-region plasma as a tracer in different heights, Z. Meteorol., 26, 1-6, 1976.

Fleming, E. L., Chandra, S., Barnett, J. J., and Corney, M.: Zonal mean temperature, pressure, zonal wind and geopotential height as function of latitude, Adv. Space. Res. 10, 11-59, 1990.

Hocking, W. K.: Temperatures using radar-meteor decay times, Geophys. Res. Lett., 26, 3297-3300, 1999.

Hocking, W. K., Fuller, B., and Vandepeer, B.: Real-time determination of meteor-related parameters utilizing modern digital technology, J. Atmos. Solar-Terr. Phys., 63, 155-169, 2004.

Hocking, W. K., Singer, W., Bremer, J., Mitchell, N. J., Batista, P., Clemesha, B., and Donner, M.: Meteor radar temperatures at multiple sites derived with SKiYMET radars and compared to $\mathrm{OH}$, rocket and lidar measurements, J. Atmos. Solar-Terr. Phys., 66, 585-593, doi:10.1016/j.jastp.2004.01.011, 2004.

Jacobi, Ch., Schminder, R., and Kürschner, D.: Planetary wave activity obtained from long-term (2-18 days) variations of mesopause region winds over Central Europe $\left(52^{\circ} \mathrm{N}, 15^{\circ} \mathrm{E}\right), \mathrm{J}$. Atmos. Solar-Terr. Phys., 60, 81-93, 1998.

Kürschner, D., Schminder, R., Singer, W., and Bremer, J.: Ein neues Verfahren zur Realisierung absoluter Reflexionshöhenmessungen an Raumwellen amplitudenmodulierter Rundfunksender bei Schrägeinfall im Langwellenbereich als Hilfsmittel zur Ableitung von Windprofilen in der oberen Mesopausenregion, Z. Meteorol., 37, 322-332, 1987.

Lastovicka, J.: Long-term changes and trends in the lower ionosphere, Phys. Chem. Earth, 27, 497-507, 2002.

Lastovicka, J., Fiser, V., and Pancheva, D.: Long-term trends in 
planetary wave activity (2-15 days) at $80-100 \mathrm{~km}$ inferred from radio wave absorption, J. Atmos. Terr. Phys., 56, 893-899, 1994.

Lauter, E. A. and Entzian, G.: Überwachung der tiefen Ionosphäre mit Hilfe der Quasi-Phasenhöhenmessung im Langwellenbereich $(100 \ldots .200 \mathrm{kHz})$. Proceedings of the Summer School "Untere Ionosphäre", Kühlungsborn 1964, Academy of Sciences of the DDR, Berlin, 67-97, 1966.

Lauter, E. A., Entzian, G., von Cossart, G., Sprenger, K., and Greisiger, K. M.: Synoptische Erschließung von Prozessen in der winterlichen Mesopausenregion durch bodengebundene Beobachtungsverfahren, Z. Meteorol., 27, 75-84, 1977.

Singer, W., Bremer, J., Weiß, J., Hocking, W. K., Höffner, J., Don- ner, M., and Espy, P.: Meteor radar observations at middle and arctic latitudes Part 1: Mean temperatures, J. Atmos. Solar Terr. Phys., 66, 607-616, doi:10.1016/j.jastp.2004.01.012, 2004.

Von Cossart, G.: Ein Beitrag zur synoptischen Untersuchung der atmosphärischen Struktur in der Mesopausenregion aus indirekten Phasenmessungen, PhD Thesis, Academy of Sciences of the DDR, 1976.

Von Cossart. G. and Entzian, G.: Ein Modell der Mesopausenregion zur Interpretation indirekter Phasenmessungen und zur Abschätzung von Ionosphären- und Neutralgasparametern, Z. Meteorol., 26, 220-230, 1976. 